\title{
Estudo do Desgaste Abrasivo das Resinas Compostas Disponíveis
}

\section{no Mercado Brasileiro}

\author{
Eduardo Carlos Bianchi ${ }^{\mathrm{a}}$, Paulo Roberto de Aguiar ${ }^{\mathrm{a}}$, Márcio Rodrigo Poggi ${ }^{\mathrm{a}}$, Manoel \\ Henrique Salgado $^{\text {a }}$ César Antunes de Freitas ${ }^{\mathrm{a}}$, Ana Rita Rodrigues Bianchi ${ }^{\mathrm{b}}$ \\ ${ }^{\mathrm{a}}$ Depto de Eng. Mecânica /Elétrica da Faculdade de Engenharia da UNESP, \\ 17033-360 Bauru - SP, Brasil. \\ ${ }^{\mathrm{b}}$ Departamento de Dentística, Endodontia e Materiais Dentários \\ da Faculdade de Odontologia de Bauru (FOB) - USP, 17043-101 Bauru - SP, Brasil
}

Received: September 5; 2002; Revised: March 17, 2003

\begin{abstract}
This work presents a proposal to assess the abrasive wear of composite resins available in the national market, which are materials largely used in dental clinics for functional and aesthetic tooth restorations. This was achieved by utilizing an experimental set-up on which a dynamic disc covered with proper porcelain (representing hardness close to the human teeth) wears a static disc covered with the resin tested under a constant and pre-determined load. Thus, by means of this setup and keeping a behavioral status needed to the calculus for all tests, the aggressiveness (referred as to letter k) for all tests was analyzed. Due to the fact that resin characteristic revels how weary the material has become to the abrasion process with other harder material, the strength to wear for such resins was observed. Therefore, a real classification for these materials with their strength to the abrasion wear was made, which is a very important factor in the influence on their lifetime in dental restorations. The classification in descending order for those resins is presented as following: HELIOMOLAR RO, DURAFILL, FILTEK A110, HELIO FILL, POINT 4, FLOW IT; NATURAL FLOW, SUPRAFILL, FILTEK P60, FILTEK Z250, TETRIC FLOW, REVOLUTION, PRODIGY, TETRIC CERAM, HERCULITE, FILLMAGIC, TPH, CHARISMA, Z100.
\end{abstract}

Keywords: composite resin, abrasive wear, evaluation methods, aggressiveness

\section{Introdução}

O homem está sempre em busca de melhores condições de vida, por isso desenvolve materiais capazes de reparar algumas imperfeições naturais e/ou acidentais. Sendo assim, as resinas compostas foram desenvolvidas com o objetivo de reparar as perdas de material dentário do ser humano.

Dentre os vários materiais existentes que poderiam ser utilizados para este fim, as resinas compostas foram escolhidas por apresentarem menor desgaste, maior facilidade de manuseio (são vendidas em tubos como os de uma pasta dental) e por possuírem uma grande gama de cores, possibilitando-se alcançar a semelhança com a coloração dos dentes humanos, tornando-se praticamente imperceptíveis após sua aplicação.

Contudo, o ideal seria que esses materiais restauradores odontológicos se desgastassem de modo semelhante ao es- malte dentário - o que não ocorre. E entre as várias razões que conduzem à substituição de restaurações confeccionadas com resinas compostas, encontra-se o desgaste abrasivo, que pode ser proveniente das escovações e da mastigação. Assim, surge a necessidade de estudar este fenômeno para prever o tempo de duração das resinas, pois sua substituição, quando gasta, é necessária.

O desgaste abrasivo das resinas compostas convencionais é descrito como um processo onde ocorre a esfoliação das partículas de material inorgânico e a matriz da resina é continuamente desgastada. A microabrasão da matriz ocorre sob tensão e sob a ação abrasiva do alimento, causando a exposição das partículas inorgânicas e o conseqüente aumento da tensão.

Juntamente, a fadiga mecânica é outro fator que também influencia no desgaste. Com o movimento dos dentes durante a mastigação, tensões cíclicas, juntamente com car- 
regamentos e descarregamentos, podem iniciar e propagar microtrincas.

Além disso, a deterioração das restaurações é ainda acelerada pela diferença entre os módulos de elasticidade da matriz e da carga. Observações das restaurações realizadas com estes tipos de resinas em superfícies oclusais (faces mastigatórias dos dentes) revelaram que a perda de material é normalmente uniforme.

Então, dentre os vários fatores determinantes do processo de desgaste abrasivo, encontram-se, genericamente, as características da própria resina e do preparo cavitário, assim como da restauração confeccionada e das condições das agressões a que ela for submetida.

Esses são, entre outros, alguns dos inúmeros fatores que influem na resistência mecânica das resinas compostas. Dessa forma, a análise do desgaste faz-se necessária, e para isso são apresentados dois métodos distintos: o clínico (in vivo) e o laboratorial (in vitro).

O método clínico consiste em se realizar restaurações em um determinado número de pacientes e após um certo período de tempo, normalmente bastante longo (mínimo de 2 e máximo de 6 anos), analisar qual foi o desgaste sofrido pelas resinas. Vários autores estudaram este método, dentre os quais cita-se:

Taylor et al. (1989) compararam métodos diretos e indiretos para análise do desgaste 1 de restaurações com resina composta em dentes posteriores. Em seu estudo, afirmaram que, por falta de um método in vitro adequado, vários métodos para a avaliação de tal desgaste haviam sido propostos, mas que apenas dois deles eram usados na maioria dos estudos clínicos. Um dos métodos era baseado na avaliação clínica direta, enquanto o outro era um método indireto, onde o desgaste era mensurado através de moldagens das restaurações. O método direto media o desgaste das restaurações em termos de categorias específicas de aceitação clínica, enquanto o indireto fornecia estimativas numéricas, com padrões quantitativos por comparação das restaurações desgastadas. Comentaram que não existiam trabalhos que comparassem os resultados obtidos pelos dois métodos e que os dados das pesquisas anteriores não podiam ser comparados com dados clínicos mais recentes. Sendo assim, o objetivo deste estudo foi desenvolver um fator de conversão entre os dois métodos para permitir comparações de estudos clínicos que os usassem.

Satou et al. (1992) avaliaram o desgaste in vivo e in vitro de 10 resinas compostas (6 polimerizáveis por luz visível e 4 quimicamente ativadas), juntamente com o esmalte. Tais materiais foram sujeitos, simultaneamente, à vibração e ação de deslizamento num desgaste do tipo 3 corpos, com diferentes abrasivos espalhados no disco acrílico. Comparações com micrografias de Microscopia de Varredura Eletrônica (M.E.V.) das superfícies de desgaste in vivo permitiram a determinação de condições adequadas para o teste de des- gaste in vitro. Relataram ter existido uma considerável variação no padrão de desgaste in vitro pela hidroxiapatita e pelo carborundo verde (espécies de abrasivos) usados neste estudo. Também apontaram que, com o primeiro abrasivo, o compósito híbrido abrasionou-se menos que o de micropartículas, e que foi observada uma correlação negativa entre a taxa de desgaste e os valores de dureza Knoop.

Dickinson et al. (1993) avaliaram, in vivo, o comportamento de 62 restaurações com resinas compostas, especialmente quanto ao desgaste, num período de 3 anos. Todas as restaurações foram periodicamente moldadas com vinil polisiloxano (Reprosil) e os modelos obtidos foram avaliados por meio de microscopia ótica. Durante o primeiro ano de uso, $97 \%$ das restaurações não exibiram nenhum sinal clínico de desgaste. Ao final de 2 anos, esse valor caiu para $84 \%$, e ao final de 3 anos esse valor estabilizou-se em $79 \%$. A média de desgaste foi de $45 \mu \mathrm{m}$ para a Herculite XR e de $28 \mu \mathrm{m}$ para a Herculite Incisal.

Suzuki et al. (1993) estudaram o desgaste localizado das resinas compostas em dentes posteriores, procurando reproduzir o desgaste clinicamente observável nos pontos de contato oclusal. Foram utilizados molares íntegros, preparando-se cavidades cilíndricas oclusais de $4 \mathrm{~mm}$ de diâmetro e profundidade, após a planificação dos mesmos com tiras de lixa e água para completa eliminação do esmalte. $\mathrm{O}$ desgaste foi promovido por um cilindro, através de uma agulha de aço inoxidável e a abrasão superficial por partículas de polimetil metacrilato.

Bryant et al. (1994) avaliaram o desempenho clínico de 3 tipos de resinas compostas em restaurações de dentes posteriores, num período de 3 anos. Foram utilizadas a Heliomolar Radiopaco (micropartículas), a Herculite XR (híbrida com predominância de partículas de carga delicadas) e P-30 APC (híbrida com predominância de partículas de carga maiores que as anteriores). Observou-se diferenças no desempenho clínico dessas resinas. A resina composta híbrida de partículas pequenas sofreu maior desgaste e com mais frequiência que os outros compósitos. Já as resinas híbridas de partículas grosseiras exibiam evidências de desgaste aos 3 anos.

Deve-se ressaltar que o método in vivo exige longo tempo de experimentação, sendo portanto, inviável, pois as composições das resinas ensaiadas sofriam alterações nesse período. Assim, os resultados obtidos não teriam aplicabilidade para tais resinas, pois já não existiam mais no mercado, ou existiam com uma nova composição.

Assim, torna-se importante realizar ensaios laboratoriais com as respectivas resinas para avaliar o comportamento de seu desgaste abrasivo, buscando resultados também precisos, porém mais rápidos.

Dickson (1979) mostrou que, dos vários métodos que têm sido utilizados para analisar a resistência ao desgaste abrasivo das resinas compostas e de outros materiais 
dentários, provavelmente o mais simples consistia no seguinte: colocar-se pequenas esferas $(0,4 \mathrm{~g})$ de material de restauração em uma cápsula de plástico com $0,4 \mathrm{~g}$ de abrasivo (carboneto de silício) e fazer com que a cápsula vibrasse por $3 \mathrm{~min}$. O desgaste era então determinado conforme ocorria a perda de peso das esferas. Este método detectava diminuições significativas. Também mostrou-se que o valor da abrasão do "Silicap" era aproximadamente o mesmo que os maiores valores encontrados para as resinas compostas. Este teste pioneiro indicou a necessidade de se realizar testes posteriores com a finalidade de se determinar quando os resultados laboratoriais terão relação com os encontrados clinicamente. Outro método que foi bastante utilizado, e que também é comentado por Dickson (1979), é o método da escova de dentes desenvolvido por Phillips et al. (1971), no qual utilizou uma escova de dentes mecânica para analisar o desgaste abrasivo de dois materiais utilizados em restaurações dentárias, e que já haviam sido analisados clinicamente, concluindo que tal tipo de ensaio pode analisar a resistência à abrasão causada pela escovação, mas não fornece resultados satisfatórios quanto ao desgaste oclusal.

De Gee et al. (1986), em trabalho publicado, relataram que experimentos anteriores têm enfatizado a falta de concordância entre os dados laboratoriais e os clínicos, com relação ao desgaste de resinas compostas. Salientaram ainda que, obviamente, nos vários testes laboratoriais realizados anteriormente o material não deve ter sido desgastado de um modo comparável ao modo de desgaste clínico e, provavelmente, também não consideraram, simultaneamente, um número suficiente de variáveis. Neste estudo, os autores propuseram-se a desenvolver uma máquina capaz de analisar o desgaste abrasivo de resinas compostas, onde as variáveis consideradas podiam ser controladas, de modo que os resultados obtidos pudessem ser comparados aos obtidos clinicamente. Concluíram seu trabalho dizendo que a máquina construída oferece resultados realísticos, mas outras variáveis ainda devem ser consideradas para a obtenção de melhores resultados.

Pallav et al. (1988) apresentaram um método de simulação do desgaste de materiais restauradores que consistia no uso de uma máquina com dois tambores cilíndricos que rodavam um contra o outro, impulsionados por dois motores acoplados a seus respectivos eixos. Um tambor acomodava as amostras a serem testadas e o outro, era pressionado contra o de testes, com uma força de $15 \mathrm{~N}$. A análise do desgaste era efetuada por meio de um perfilômetro computadorizado, constatando-se boa correlação com os dados clínicos.

Coelho (1991) estudou as propriedades da dressagem de rebolos, em operações de retificação de precisão. O método por ele desenvolvido consistia em se manter um disco estático (confeccionado com o material da peça cilíndrica que seria retificada - o agredido), estando imobilizado no eixo horizontal da extremidade de uma balança própria, pressionado contra a superfície similar de um determinado rebolo (agressor), sob ação de uma força normal constante. Com este girando por um tempo determinado, verificava-se o desgaste do agressor e/ou o agredido. O deslocamento sofrido pelo disco estático, em direção ao rebolo, era continuamente registrado para permitir a realização dos cálculos. Embora este trabalho não tivesse, até aquela data, nenhuma previsão de utilização para desgastar resina, foi o precursor de um método desenvolvido posteriormente para este fim.

Matsumura et al. (1994) estudaram o desgaste de 4 tipos de resinas compostas fotopolimerizáveis (Cesead, Elcebond, New Metacolor e Thermoresin LC) através do teste de desgaste tipo 3 corpos desenvolvido, sendo que este instrumento era capaz de prognosticar o desgaste oclusal das resinas compostas posteriores. Os autores observaram que todas as resinas testadas exibiram melhor resistência ao desgaste do que as resinas sem partículas; como as fotomicrografias dos 4 compósitos exibiram partículas de carga expostas, após o teste, afirmaram que isto apontava diferenças na resistência ao desgaste entre a matriz de resina e as partículas de carga. Relataram ainda que, entre os 4 materiais testados, Cesead e New Metacolor pareciam ser aceitáveis como materiais para uso em restaurações de dentes posteriores e anteriores, porém não tendo ainda sido comprovado ser adequado o uso de resinas compostas, quanto à sua resistência ao desgaste nas áreas de contato oclusal intenso, como áreas de relação cêntrica, onde deveriam ainda ser usados materiais metálicos. Após analisar os resultados, concluíram que a resistência ao desgaste das resinas compostas é diretamente influenciada pelas propriedades do ambiente ao qual está submetida e pelas propriedades de seus materiais constituintes, como o tamanho de suas partículas (cargas), por exemplo.

Wassell et al. (1994) afirmaram que o desgaste dos materiais restauradores é um fenômeno complexo que envolve componentes abrasivos, adesivos, de fadiga e de corrosão; além disso, apontaram que uma importante dificuldade nos testes do tipo dois-corpos era que, se o esmalte fosse usado como o agente de abrasão, suas características variavam de um espécime para outro. Sendo assim, como o agente de abrasão era um fator de importante influência neste processo, afirmou que, para vencer os problemas de heterogeneidade dos espécimes decorrentes da utilização do esmalte, escolheu um material cerâmico, como um substituto em potencial deste último, pelo fato da dureza de ambos serem semelhantes.

Dias (1995), em seu trabalho de graduação, apresentou cálculos matemáticos que nortearam o desenvolvimento de um método para avaliar o desempenho de resinas restauradoras, assim como seu respectivo banco de ensaios, que 
incluía um software.

Bianchi et al. (1996) modificaram o método do disco retificado de Coelho (1991), adaptando-o para a avaliação de materiais restauradores odontológicos. As modificações introduzidas, basicamente consistiram de: 1) substituição dos discos agressor e agredido (respectivamente, rebolo e material da peça a ser retificada) por discos metálicos revestidos de um mesmo material restaurador odontológico, nestes primeiros ensaios duas resinas compostas; 2) uma alteração da localização do disco agressor, agora girando preso ao eixoárvore de um cabeçote de testes; e 3) uma alteração dos diâmetros dos discos, que passaram a ser iguais.

Yap et al. (1997) desenvolveram um mecanismo de análise de desgaste que se compõe de uma mesa giratória com um rasgo em forma de anel onde é alojado o material em estudo. Um pino de ponta esférica de $2 \mathrm{~mm}$ de diâmetro, recoberto com abrasivo, é preso a um suporte que possui movimento vertical livre por meio de uma guia. No suporte é aplicada uma carga constante de $15 \mathrm{~N}$ provocando uma pressão de aproximadamente 19 MPa na superfície do material. A mesa onde está o material a ser estudado gira a uma velocidade angular de $160 \mathrm{rpm}$. Cada material é testado por duas horas, o que corresponde a 19200 ciclos de desgaste. Durante o teste, água foi dirigida ao ponto de contato para remover as partículas resultantes do desgaste e promover o desgaste por "terceiro corpo" (entre as partículas removidas e a superfície ensaiada para simular o material orgânico entre os dentes existente na mastigação). O desgaste é então medido por meio do perfil de rugosidade (devido ao seu reduzido valor) entre as superfícies sem desgaste e a superfície desgastada, usando-se um rugosímetro colocado radialmente ao anel do material ensaiado. Também desenvolveram e fabricaram um simulador do sistema de mastigação para analisar o desgaste provocado pelo movimento intra-oral dos dentes durante a mastigação. $\mathrm{O}$ desgaste proporcionado por este mecanismo é também medido utilizando-se um rugosímetro, a cada $1 \mathrm{~mm}$, de lado a lado na superfície desgastada. Os autores chegaram à conclusão de que, dentre os materiais ensaiados, o DISPERSALLOY é o mais duro e o mais resistente ao desgaste sem impacto, sendo menos resistente que os demais no desgaste por impacto. E o desgaste das resinas compostas está diretamente relacionado com a quantidade e tipo de suas partículas.

Wang et al. (1998) modificaram um tribômetro (aparelho utilizado para medir a intensidade do atrito entre duas superfícies) de forma que ficasse como o aparato de um teste de desgaste do tipo pino-no-disco. Uma amostra de material dentário restaurador foi utilizada como pino (agulha) e um rebolo de diamante como o abrasivo. Ambas, forças normais e de atrito, foram registradas no decorrer do teste. A razão volumétrica de desgaste foi calculada pela mudança do comprimento e área de secção transversal da amostra. O modo de falha na superfície desgastada foi analisado utilizando-se fotografias de M.E.V.. A razão de desgaste específico e coeficientes de atrito de três produtos restauradores dentais comerciais (Z-100 (3M), Renamel (Cosmedent) e Clearfil AP-X (Kuraray)), foram comparados. Pela combinação dos resultados do teste de desgaste com a observação microscópica das superfícies desgastadas, pôde-se determinar os mecanismos primários de desgaste e interpretar os dados sob as condições do teste. Os resultados foram racionalizados em termos do espaçamento entre partículas, arrancamento das mesmas e fratura frágil dos materiais. Enfatizou-se que esse trabalho não correlaciona tão bem os testes in vitro a um estudo clínico, contudo é um bom controle experimental das condições e pode identificar os fatores que levam o material a iniciar o mecanismo de desgaste.

Os métodos laboratoriais também têm sofrido críticas, não só pela sua complexidade de planejamento e de execução, como pela dificuldade de comparação de seus resultados, dadas as variações metodológicas adotadas em cada trabalho. Justifica-se assim a necessidade do desenvolvimento de um padrão laboratorial confiável, que forneça os resultados almejados em curto período de tempo.

\section{Metodologia}

O método utilizado para a avaliação do desgaste de resinas compostas baseou-se no estudo da agressividade da superfície de restaurações dentárias confeccionadas com essas resinas. Para a determinação desse fator, foi reproduzido e adaptado o método do disco retificado, desenvolvido por Coelho (1991).

Este método utiliza um banco de ensaios (Fig. 1) acoplado a um cabeçote de testes que possui um eixo para fixação de um disco agressor, o qual gira com uma rotação pré-estabelecida proporcionada por um motor elétrico. $\mathrm{O}$ conjunto banco de ensaios/cabeçote de testes (apresentado na Fig. 2), encontra-se posicionado sobre a mesa de uma retificadora tangencial plana, necessária à uniformização do disco agressor dinâmico. Seu funcionamento consiste em manter posicionado um disco fixo (ou seja, sem rotação), revestido em toda a sua circunferência (superfície) externa com resina composta que se deseja analisar, contra um disco dinâmico. Tal revestimento constitui-se pela polimerização de pequenos incrementos de resina depositados nessa região, até que se recubra toda a área.

Após a regularização da superfície da resina (com um rebolo convencional de óxido de alumínio), o disco fixo é pressionado contra a superfície do dinâmico (confeccionado com porcelana e retificado com um rebolo diamantado), sob uma força normal constante, através de uma carga préestabelecida de $16 \mathrm{~N}$. O posicionamento dos discos é mos- 


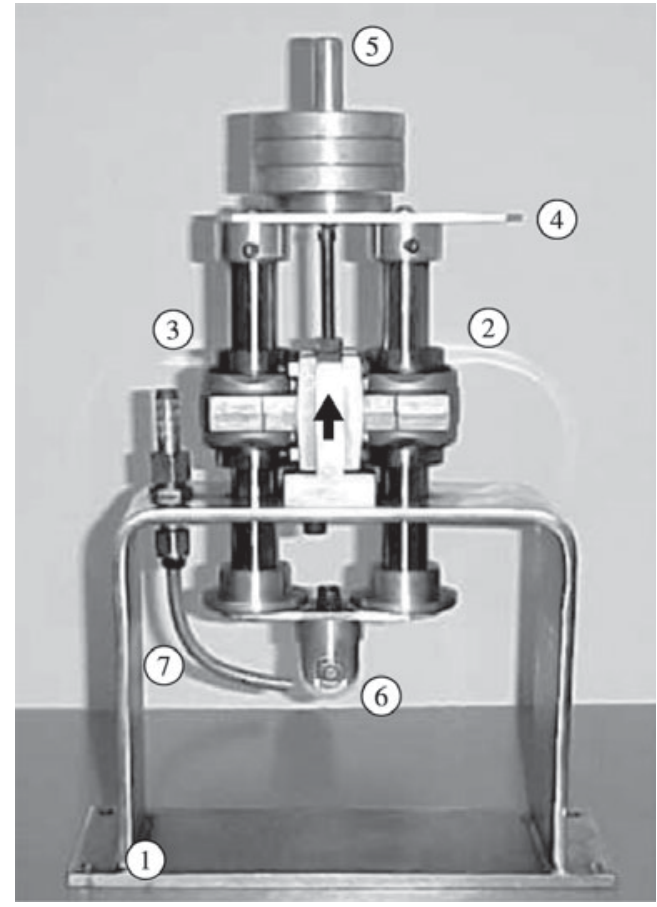

Figura 1. Banco de ensaios mostrado em detalhes. Elementos: base (1), dispositivo-guia (2), hastes cilíndricas (3), trave para registro de deslocamento (4), haste cilíndrica central (5), suporte do disco estático (6) e mangueira (7).

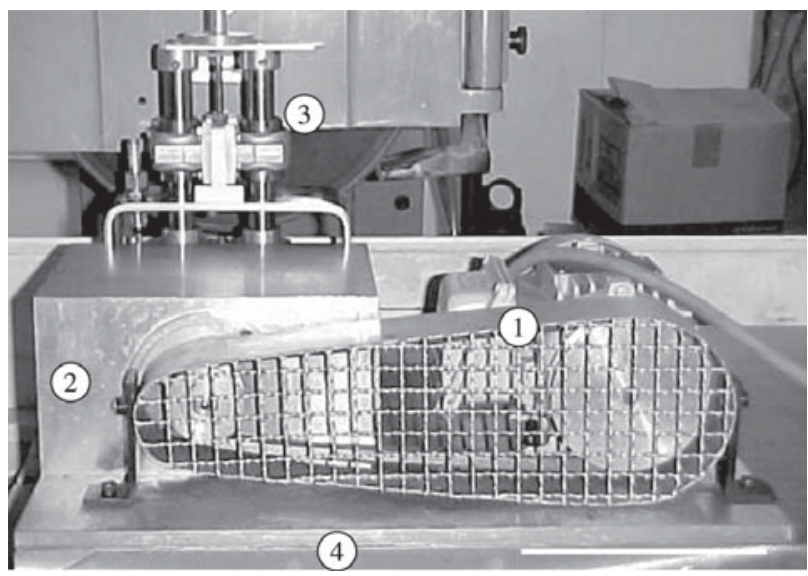

Figura 2. Fotografia do conjunto banco de ensaios/cabeçote de testes, juntamente com o motor de acionamento, posicionados sobre a mesa da máquina retificadora. Elementos: motor elétrico (1), o cabeçote (2), o sistema cursor de deslocamento (3) e a placa de aço (4) que serve de base para o conjunto descrito. trado na Fig. 3.

O deslocamento do disco fixo contra o disco dinâmico, à medida que ocorre o desgaste da resina, foi registrado em função do tempo, através de um medidor eletrônico de deslocamento conectado a uma placa de aquisição em um computador.

Através do desgaste da resina, o deslocamento do dispositivo é registrado em forma de sinais de tensão elétrica, sendo estes enviados à placa que, com uma equação de calibração previamente efetuada e implementada no programa de aquisição de dados, desenvolvido através do software Labview, calcula o respectivo deslocamento real do dispositivo, gerando um gráfico como o apresentado na Fig. 4.

Nota-se, pelo gráfico, que inicialmente há um período em que não há deslocamento do dispositivo. E isso deve-se ao tempo transcorrido entre o acionamento do programa de aquisição de dados e o instante de acionamento do motor do cabeçote de ensaios. (Obs.: O pequeno deslocamento observado nessa região, deve-se a uma pequena variação de tensão da rede ocorrida apenas inicialmente - devido à sensibilidade do equipamento - quando ainda não deu-se o contato do banco de ensaios com o dispositivo de aquisição de dados. Após iniciar-se tal contato, há uma uniformização da tensão enviada à placa de aquisição, devido à carga imposta ao dispositivo eletrônico pelo banco de ensaios). Dessa forma, este é um período que pode ser desconsiderado, sendo que não faz parte do ensaio propriamente, mas constitui o tempo ocioso antes do início do mesmo.

À partir daí, inicia-se o desgaste da resina, ou seja, o ensaio propriamente dito, e isso é percebido pela curva crescente mostrada no mesmo gráfico. Esse desgaste ocorre até um determinado ponto, cessando-se (isso é notado pelo comportamento constante final da curva), devido ao aumento da área de contato entre os dois discos (estático e dinâmico).

Essa parte final do gráfico (onde não há desgaste) também não é de interesse, pois deseja-se avaliar a agressividade das resinas, a qual ocorre apenas quando está havendo o desgaste. Dessa forma, desconsidera-se também esse comportamento final para efeito dos cálculos.

Sendo assim, a única parte do gráfico que interessa para esse tipo de ensaio, é a parte curva, onde há o real desgaste. O tempo de ensaio, então, deve ser considerado à partir de onde começou a ocorrer tal desgaste, até o momento em que o mesmo cessou-se.

Seguindo de acordo com a metodologia proposta, devese elevar o tempo de ensaio a $2 / 3$ para se obter a tangente da curva de deslocamento do dispositivo, a qual o coeficiente angular é utilizado na equação para o cálculo da agressividade. A Fig. 5 mostra o gráfico obtido após realizada tal consideração. 


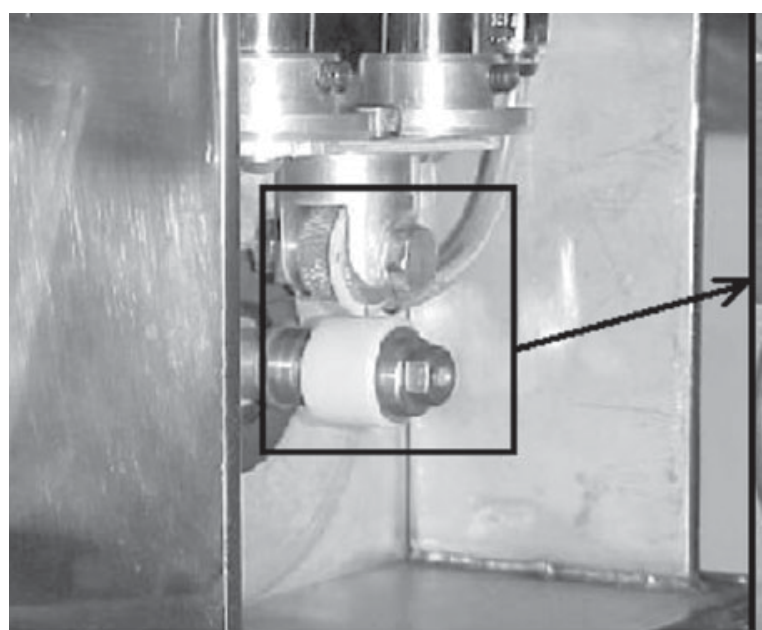

a)

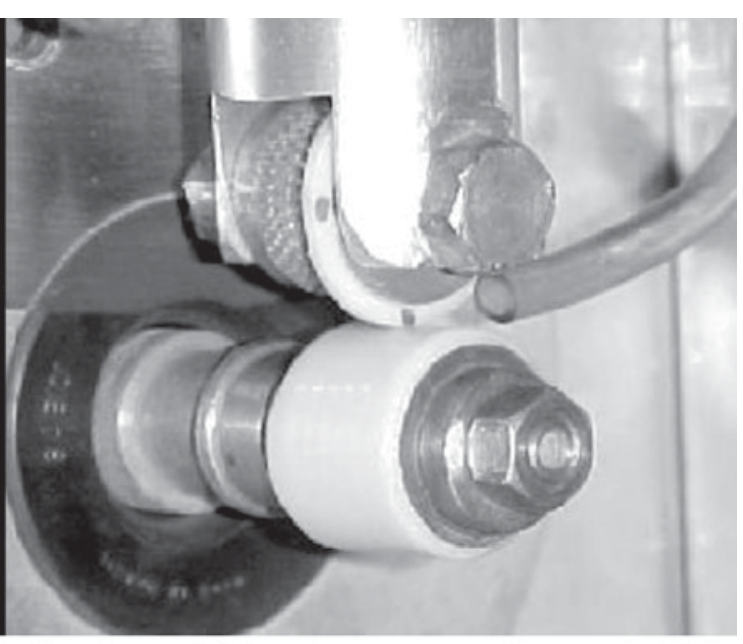

b)

Figura 3. Fotografia com o posicionamento dos discos estático e dinâmico no conjunto banco de ensaios/cabeçote de testes (a); detalhe (b) mostra o contato da resina presente no disco estático (superior) com a cerâmica do disco dinâmico (inferior).

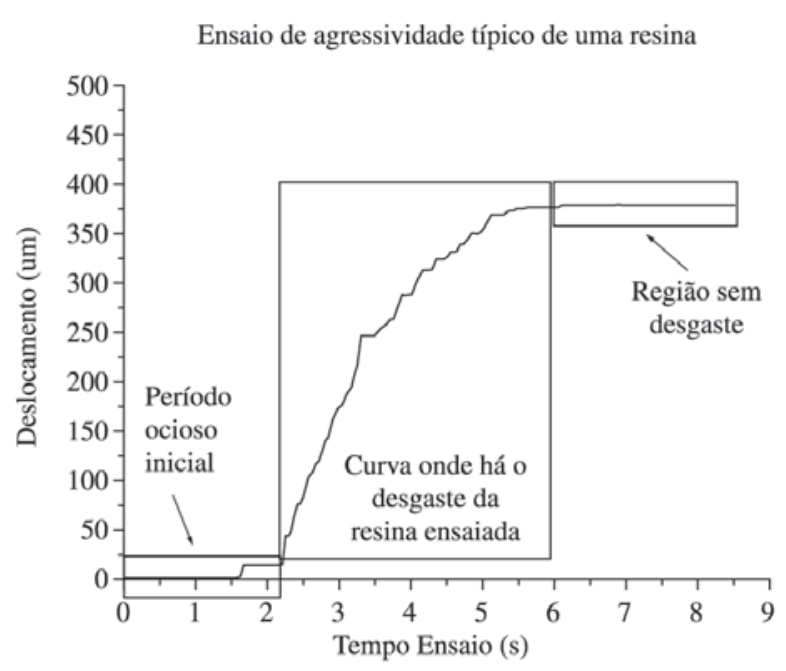

Figura 4. Gráfico típico de deslocamento do dispositivo em função do tempo, obtido nos ensaios de agressividade das resinas compostas.

Ainda a partir deste último gráfico, com o cálculo do coeficiente angular da reta tangente, obtém-se, através da Eq. 1 (obtida por um desenvolvimento matemático adequado à estrutura do banco de ensaios, seguindo o procedimento utilizado por Coelho (1991)), e dos parâmetros utilizados no ensaio (largura do disco estático $(b=1,5 \mathrm{~mm}$ ), raio do disco estático para o respectivo ensaio (r) e força normal aplicada $\left(\mathrm{F}_{\mathrm{n}}=16 \mathrm{~N}\right)$ ), a agressividade $(\mathrm{k})$ da resina em questão.

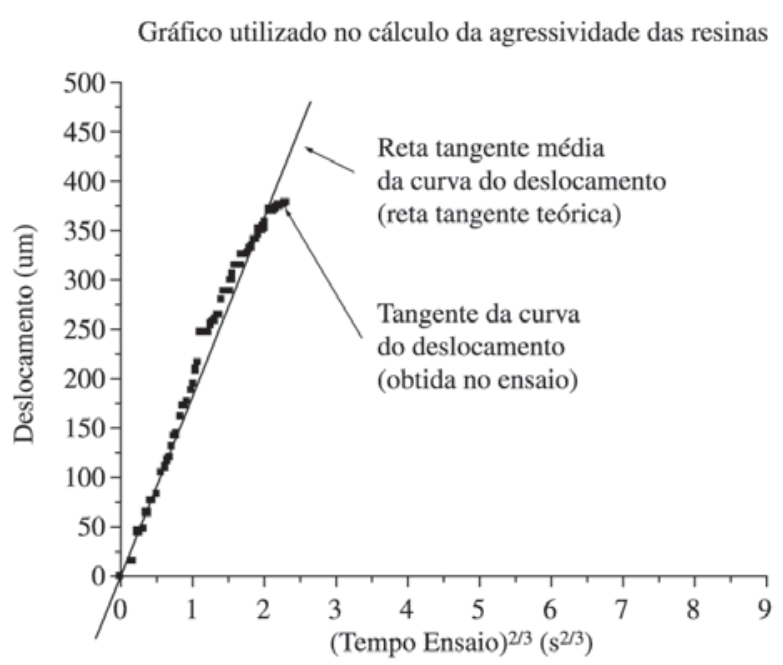

Figura 5. Gráfico mostrando a tangente da curva de desgaste das resinas, a qual seu coeficiente angular é utilizado no cálculo da respectiva agressividade.

$$
k=\left\{\left[2 \cdot b \cdot(4 r)^{0,5}\right] / 3 \cdot F_{n}\right\} \cdot\left(a_{1}\right)^{2 / 3}
$$

onde: $\mathrm{k}\left(\mathrm{mm}^{3} / \mathrm{N} . \mathrm{s}\right)$ é a agressividade da resina; $\mathrm{F}_{\mathrm{n}}(\mathrm{N})$ a força normal necessária à remoção de material; b (mm) a largura dos discos fixos; $r$ (mm) o raio dos discos; e $a_{1}$ o coeficiente angular da reta de regressão linear.

A Fig. 6 mostra um esquema geral da metodologia utilizada.

Para a comparação dos tipos de resina quanto à 
Desenho Esquemático do banco de ensaios utilizados para avaliação de desgaste de resinas

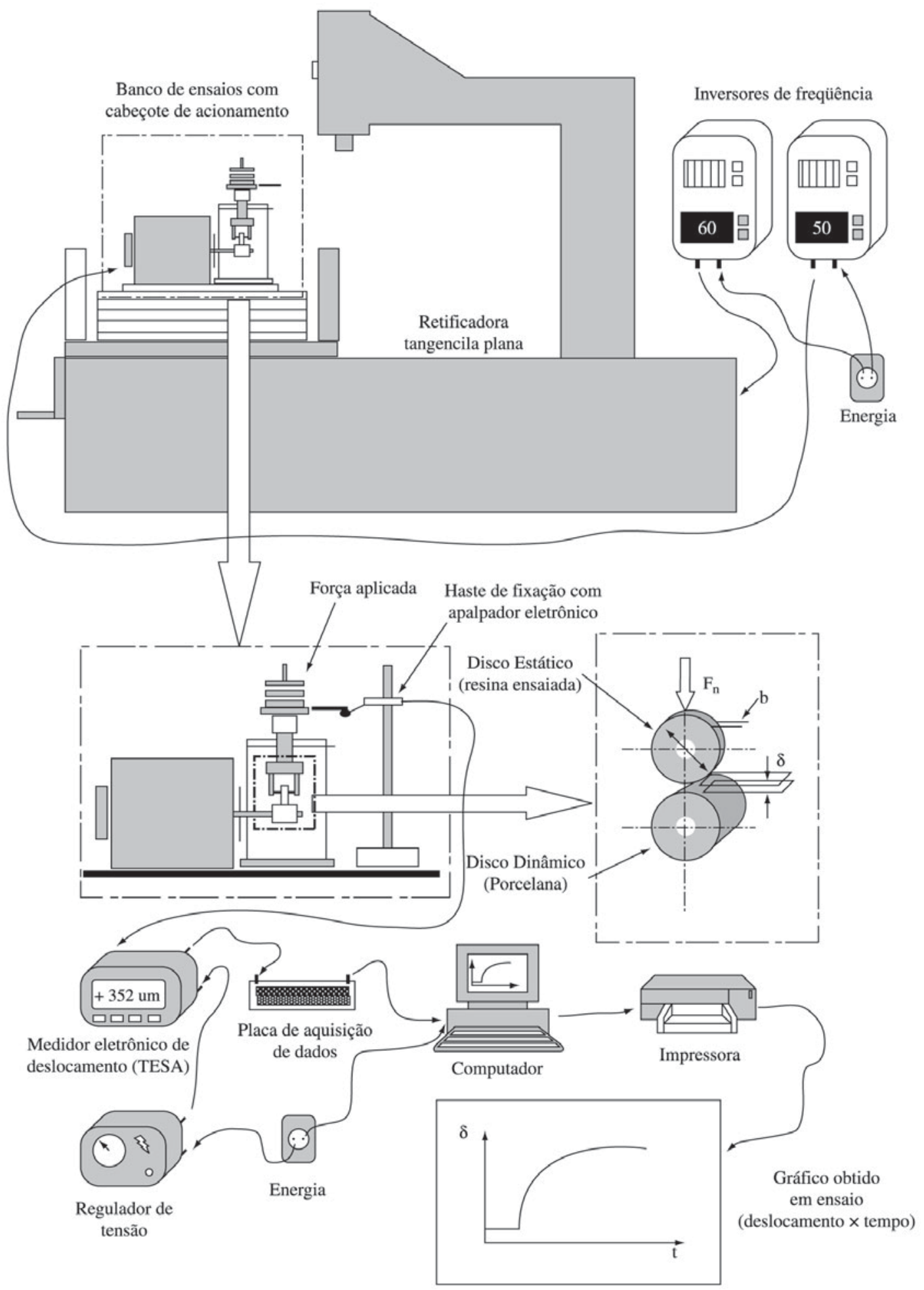

Figura 6. Resumo Esquemático da Metodologia utilizada nos ensaios. 
agressividade, utilizou-se a técnica estatística da Análise de variância seguida do teste de Tukey, de acordo com Costa Neta (1977).

\section{Resultados e Discussão}

Os resultados obtidos nos ensaios são apresentados na Tabela 1.

Tabela 1. Resultados obtidos nos ensaios de agressividade das resinas.

\begin{tabular}{lccr}
\hline $\begin{array}{l}\text { Resinas } \\
\text { Ensaiadas }\end{array}$ & $\begin{array}{c}\text { Agressividade } \\
\text { Média }\left(\mathrm{mm}^{3} / \mathrm{N} . \mathrm{s}\right)\end{array}$ & $\begin{array}{c}\text { Desvio Padrão } \\
\left(\mathrm{mm}^{3} / \mathrm{N} . \mathrm{s}\right)\end{array}$ & $\begin{array}{r}\text { Variância } \\
\left(\mathrm{mm}^{3} / \mathrm{N} . \mathrm{s}\right)\end{array}$ \\
\hline Z100 & 0,0809 & 0,0109 & $8,93 \mathrm{E}-05$ \\
Charisma & 0,0720 & 0,0146 & $1,61 \mathrm{E}-04$ \\
TPH & 0,0564 & 0,0051 & $2,12 \mathrm{E}-05$ \\
Fillmagic & 0,0496 & 0,0036 & $1,06 \mathrm{E}-05$ \\
Herculite & 0,0389 & 0,0035 & $9,62 \mathrm{E}-06$ \\
Tetric Ceram & 0,0374 & 0,0031 & $7,44 \mathrm{E}-06$ \\
Prodigy & 0,0360 & 0,0027 & $5,96 \mathrm{E}-06$ \\
Revolution & 0,0321 & 0,0059 & $2,78 \mathrm{E}-05$ \\
Tetric Flow & 0,0319 & 0,0022 & $3,99 \mathrm{E}-06$ \\
Filtek Z250 & 0,0309 & 0,0052 & $2,17 \mathrm{E}-05$ \\
Filtek P60 & 0,0232 & 0,0071 & $4,42 \mathrm{E}-05$ \\
Suprafill & 0,0215 & 0,0043 & $1,70 \mathrm{E}-05$ \\
Natural Flow & 0,0154 & 0,0032 & $7,50 \mathrm{E}-06$ \\
Flow It & 0,0113 & 0,0037 & $1,22 \mathrm{E}-05$ \\
Point 4 & 0,0072 & 0,0023 & $4,52 \mathrm{E}-06$ \\
Helio Fill & 0,0015 & 0,0004 & $7,42 \mathrm{E}-08$ \\
Filtek A110 & 0 & 0 & 0 \\
Durafill & 0 & 0 & 0 \\
Heliomolar Ro & 0 & 0 & 0 \\
\hline
\end{tabular}

A partir desses resultados, utilizou-se o Teste de Tukey - 5\%, a fim se verificar possíveis semelhanças e/ou diferenças significantes entre as resinas ensaiadas.

Sendo assim, a Tabela 2 mostra as 16 resinas que sofreram desgaste (pois as 3 outras que não obteve-se desgaste pelo método utilizado, não devem ser comparadas a essas, sendo que não possuem valores de agressividade lidos no dispositivo de aquisição, não existindo, portanto, parâmetros a serem comparados) agrupadas por semelhanças entre seus valores médios de agressividade. Assim, na referida tabela, letras iguais significam desgastes semelhantes, ou seja, possuem um comportamento similar quanto ao desgaste.

A análise dessa tabela indica que os mecanismos de desgaste da maior parte das resinas são semelhantes, ou seja, há vários grupos com um número razoável de resinas, evidenciando que não há diferenças significativas entre suas agressividades. É o caso, por exemplo, do grupo formado por: Filtek Z250, Tetric Flow, Revolution, Prodigy, Tetric Ceram e Herculite, dentre outros.

Na sequiência, apresenta-se na Fig. 7, o gráfico que mostra a classificação decrescente das resinas em função de suas agressividades bem como os respectivos desvios-padrão, construído a partir dos valores da Tabela 1 .

Como a agressividade varia de maneira inversa à resistência ao desgaste abrasivo das resinas, ou seja, aquela com maior agressividade é a que sofreu maior desgaste, sendo portanto a menos resistente, de acordo com a Fig. 7, apresenta-se a classificação decrescente (da mais resistente para a menos resistente) das resinas, segundo o critério de resistência mecânica: HELIOMOLAR RO, DURAFILL e

Tabela 2. Resultado do Teste de Tukey (5\%) aplicado às resinas.

\begin{tabular}{|c|c|c|c|c|c|c|c|c|c|c|c|c|c|c|c|c|}
\hline $\begin{array}{l}\text { Resinas } \\
\text { Ensaiadas }\end{array}$ & $\begin{array}{c}\text { Agressividade } \\
\text { Média }\left(\mathrm{mm}^{3} / \mathrm{N} . \mathrm{s}\right) *\end{array}$ & & & & & pos & e R & $\begin{array}{l}\text { inas } \\
\text { iste }\end{array}$ & $\begin{array}{l}\text { eme } \\
\text { Test }\end{array}$ & Iant & $\begin{array}{l}\text { col } \\
y(5\end{array}$ & rela & & & & \\
\hline Helio Fill & 0,0015 & A & & & & & & & & & & & & & & \\
\hline Point 4 & 0,0072 & A & B & & & & & & & & & & & & & \\
\hline Flow It & 0,0112 & A & B & $\mathrm{C}$ & & & & & & & & & & & & \\
\hline Natural Flow & 0,0154 & A & B & $\mathrm{C}$ & $\mathrm{D}$ & & & & & & & & & & & \\
\hline Suprafill & 0,0215 & & & & $\mathrm{D}$ & $\mathrm{E}$ & & & & & & & & & & \\
\hline Filtek P60 & 0,0232 & & & & $\mathrm{D}$ & $\mathrm{E}$ & $\mathrm{F}$ & & & & & & & & & \\
\hline Filtek Z250 & 0,0309 & & & & & E & $\mathrm{F}$ & G & & & & & & & & \\
\hline Tetric Flow & 0,0319 & & & & & $\mathrm{E}$ & $\mathrm{F}$ & G & $\mathrm{H}$ & & & & & & & \\
\hline Revolution & 0,0321 & & & & & E & $\mathrm{F}$ & $\mathrm{G}$ & $\mathrm{H}$ & I & & & & & & \\
\hline Prodigy & 0,0360 & & & & & & & $\mathrm{G}$ & $\mathrm{H}$ & I & $\mathrm{J}$ & & & & & \\
\hline Tetric Ceram & 0,0374 & & & & & & & G & $\mathrm{H}$ & I & $\mathrm{J}$ & $\mathrm{K}$ & & & & \\
\hline Herculite & 0,0389 & & & & & & & $\mathrm{G}$ & $\mathrm{H}$ & I & $\mathrm{J}$ & $\mathrm{K}$ & $\mathrm{L}$ & & & \\
\hline Fillmagic & 0,0496 & & & & & & & & & & & $\mathrm{~K}$ & $\mathrm{~L}$ & M & & \\
\hline TPH & 0,0564 & & & & & & & & & & & & & M & $\mathrm{N}$ & \\
\hline Charisma & 0,0720 & & & & & & & & & & & & & & & $\mathrm{O}$ \\
\hline Z100 & 0,0809 & & & & & & & & & & & & & & & $\mathrm{O}$ \\
\hline
\end{tabular}

* médias acompanhadas de mesma letra não indicam diferença estatística significativa. 


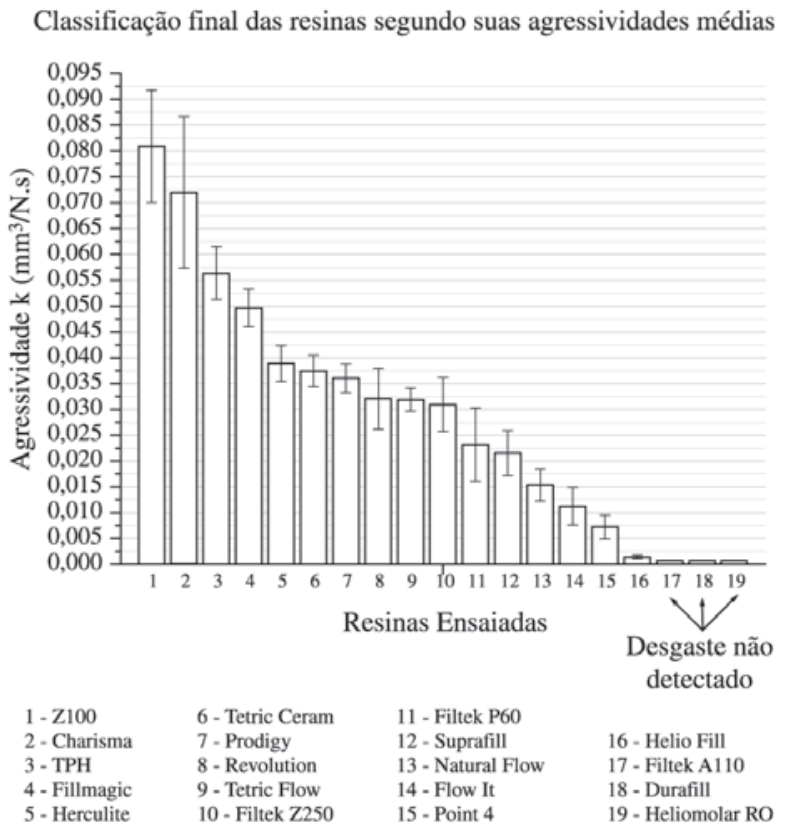

Figura 7. Gráfico com a classificação final das 19 resinas compostas ensaiadas em função de suas agressividades médias.

FILTEK A110 (todas como sendo as mais resistentes - não se obteve deslocamento, então não é possível distinguir resistência entre elas); HELIO FILL; POINT 4; FLOW IT; NATURAL FLOW; SUPRAFILL; FILTEK P60; FILTEK Z250; TETRIC FLOW; REVOLUTION; PRODIGY; TETRIC CERAM; HERCULITE; FILLMAGIC; TPH; CHARISMA; Z100.

Deve-se salientar que os valores numéricos de agressividades obtidos para as resinas são pertinentes à metodologia e parâmetros de ensaio utilizados, servindo-se então apenas como índices comparativos para a classificação delas.

\section{Conclusões}

Dentre os dois métodos de avaliação do desgaste abrasivo de resinas compostas, verifica-se que o método clínico, apesar de ser um método que utiliza as reais condições a que são submetidos esses materiais (ambiente bucal, caracterizado pela ação da saliva, bem como ação mastigatória), é um método de difícil concretização, pois depende não só do experimento em si, mas também da colaboração por parte de pacientes, sendo que é necessário contar com o retorno dos mesmos ao consultório para análise das restaurações realizadas em cada um. Além disso, é um método de difícil análise dos resultados, sendo que há uma grande variabili- dade de hábitos alimentares entre os pacientes, gerando condições adversas nas respectivas restaurações de cada um.

Dessa forma, não se encontram parâmetros fixos que possam ser utilizados para a análise dos resultados como um todo, pois existem pacientes que têm hábitos alimentares mais severos que outros, provocando maiores índices de desgaste para um mesmo tipo de resina utilizada nas restaurações, em um mesmo período de tempo. Sendo assim não se consegue comparar e predizer qual resina seria a mais eficiente.

Então, o único meio de se realizar comparações confiáveis através desse método de avaliação, seria controlar os hábitos alimentares de cada pessoa, além de garantir sua presença no consultório para avaliações periódicas em intervalos de tempo pré-determinados, o que é extremamente difícil.

Por esses e outros motivos, o método laboratorial vem superando o método clínico quanto à confiabilidade e facilidade de obtenção de seus resultados; método este que consiste na realização de experimentos em laboratórios, simulando as condições bucais a que são submetidas as resinas. Dessa forma, tenta-se obter, da maneira mais próxima possível, as condições de desgaste que sofrem os materiais restauradores, no caso, as resinas. Vem sendo bastante difundido, e inúmeros autores, como apresentado no trabalho, estão criando diferentes formas (maneiras), ou aparatos, para efetuar a avaliação. Contudo, tais maneiras variam muito de autor para autor, apesar de todas convergirem para um único propósito: avaliar, principalmente, o desgaste abrasivo das resinas, sendo que este é o maior fator contribuinte para a perda de material das restaurações dentárias.

E dentre os diversos aparatos, ou dispositivos, criados por tais autores para medir o desgaste das resinas compostas, estão, entre outros: métodos de desgaste do tipo três corpos (onde uma pasta abrasiva simula a película de alimentos, acentuando o desgaste); dispositivos (bocas artificiais) que simulam os movimentos mastigatórios reais ocorridos na boca humana, além da inserção de compósitos com características aproximadas as da saliva; aparelhos onde um disco (ou tambor cilíndrico) contendo a resina é pressionado contra outro que tem rotação contrária; e dispositivos "pino no disco", onde um pino de ponta esférica, recoberto por abrasivo, atua, através de uma determinada pressão, no material a ser ensaiado que é disposto em um rasgo circular, em forma de anel, sobre uma mesa giratória.

Todos estes métodos apresentados mostram diferentes variáveis consideradas, mas deve-se lembrar também que existem poucos dados clínicos com relação ao desgaste das diferentes resinas compostas. Torna-se então muito difícil dizer qual dos testes se correlaciona melhor com os experimentos clínicos. E essa correlação, para diferentes tipos de materiais restauradores (como o amálgama e as resinas com- 
postas), servem como guia para a análise dos métodos. Sendo assim, dados mais detalhados das variações dos métodos clínicos comparando as resinas compostas também tornam-se necessários.

Em resumo, uma grande variedade de testes está surgindo para analisar alguma propriedade, ou uma combinação de propriedades das resinas compostas. E o estudo dos mecanismos controladores destas propriedades em ambos os tipos, clínico e laboratorial, devem ser aprimorados, pois apenas com o desenvolvimento de ambos os métodos podese compará-los e chegar a um padrão confiável de análise do desgaste abrasivo desses materiais.

E dentre esses métodos, surge o presente trabalho, comprovando a teoria apresentada por diversos autores já citados, a qual salienta que o método in vitro de análise para resinas compostas tem uma grande importância se comparado ao método clínico, sendo que apresenta resultados significativos através de experimentos de simples execução e em curtos períodos de tempo.

E este método de ensaio utilizado, baseado no princípio desenvolvido por Coelho (1991), surtiu resultados esperados, sendo que o banco de ensaios, foi sensível à aquisição e detecção dos diversos comportamentos obtidos para cada tipo de resina, mostrando-se, portanto, aplicável e confiável.

Sendo assim, a classificação obtida para as resinas ensaiadas é considerada válida para utilização por dentistas e protéticos como forma de averiguar quais têm melhor comportamento quanto ao desgaste abrasivo, perante inúmeras outras.

\section{Agradecimentos}

Os autores expressam seus agradecimentos a FAPESP (Fundação de Amparo à Pesquisa do Estado de São Paulo) pelo apoio concedido para a realização do presente trabalho.

\section{Referências Bibliográficas}

1. Bianchi, E.C. et al. Avaliação do desgaste abrasivo de resinas compostas, In: Congresso de Eng. Mecânica Norte/Nordeste, 4, Recife. Assoc. Brasileira de Ciências Mecânicas, V.1., Rio de Janeiro, p. 169-74, 1996.

2. Bryant, R.W.; Hodge, K.V. A. Clinical Evaluation of Posterior Composite Resin Restorations, Australian Dental Journal, V.39, No. 2., p. 77-81, 1994.

3. Coelho, R.T. Estudo experimental da propriedade de dressagem de rebolos na retificação de precisão usando o método do disco retificado, Dissertação (Mestrado) Escola de Engenharia de São Carlos, Universidade de São Paulo, São Carlos, p. 122, 1991.

4. Costa Neto, P.L.O. Estatística. Editora Edgard Blücher
Ltda. São Paulo. p. 264, 1977.

5. De Gee, A.J.; Pallav, P.; Davidson, C.L. Effect of Abrasion Medium on Wear of Stress-bearing Composites and Amalgam in vitro, J. Dent. Res. V.65, No. 5, p. 654-658, 1986.

6. Dias, A.C.P. Estudo e desenvolvimento de um método e um banco de ensaios para a avaliação do desempenho de resinas para restaurações odontológicas, assistido por computador, Monografia (Graduação) - Faculdade de Engenharia e Tecnologia, Universidade Estadual Paulista, Bauru, p. 143, 1995.

7. Dickson, G. Physical and Chemical Properties and Wear, J. Dent. Res., v. 58, n. 5, p. 1535-1543, 1979.

8. Dickinson, G.L.; Gerbo, L.R.; Leinfelder, K.F. Clinical evaluation of a highly wear resistant composite, Amer. J. Dent., v. 6, n. 2, p. 85-87, 1993.

9. Matsumura, H.; Leinfelder, K.F. Three-body wear of four types of light-activated composite resin veneering materials, Quintessence Int., v. 25, n. 6, p. 425-30, 1994.

10. Pallav, P.; Davidson, C.L.; DE GEE, A.J.; Wear rates of composites, an amalgam, and enamel under stressbearing conditions, J. Prosth. Dent., v. 59, n. 4., p. 426429, 1988.

11. Phillips, R.W.; Avery, D.R.; Mehra, R.; Swartz, M.L.; Mccune, R.J. One-year Observations on a Composite Resin for Class II Restorations, J. Prosth Dent, v. 26, p. 68-77, 1971.

12. Satou, N.; Khan, A.M.; Satou, K.; Satou, J.; Shintani, H.; Wakasa, K.; Yamaki, M. In-vitro and in-vivo Wear Profile of Composite Resins, Journal of Oral Rehabilitation, v. 19, p. 31-37, 1992.

13. Suzuki, S.; Leinfelder, K.F. Localized wear and marginal integrity of posterior resin composites, Amer. J. Dent., v. 6, n. 4, p. 199-203, 1993.

14. Taylor, D.F.; Bayne, S.C.; Sturdevant, J.R.; Wilder, A.D. Comparison of direct and indirect methods for analyzing wear of posterior composite restorations, Dent. Mat., v. 5, n. 3, p. 157-60, 1989.

15. Wang, W.; Dibenedetto, A.T.; Goldberg, A.J. Abrasive wear testing of dental restorative materials, Institute of Materials Science, University of Connecticut U-136, Storrs, USA. School of Dentistry, University of Connecticut Health Center, Farmington, USA, 1998.

16. Wassell, R.W.; Mccabe, J.F.; Walls A.W.G. A Two-body Frictional Wear Test, J. Dent. Res., v. 73, n. 9, p. 15461553, 1994.

17. Yap, A.U.J.; Theo, S.H.; Hastings, G.W.; Lo, C.S. Comparative Wear Ranking of Dental Restorative Materials Utilizing Different Wear Simulation Modes, J. Oral Rehab., v. 24, p. 574-580, 1997. 